\title{
nature
} medicine

\section{Publication by press release}

Last November, Millennium Pharmaceuticals, a relatively new biotechnology company focusing on gene discovery, took the then unprecedented decision to issue a press release announcing an important research finding (the isolation of a gene involved in diabetes) - unprecedented because no details of the science were made available and no publication was scheduled. Shortly after, in January of this year, Myriad Genetics followed suit by announcing that they had discovered a putative tumor suppressor gene implicated in gliomas, and in May, Sequana Therapeutics declared that they had bagged a gene responsible for asthma. In all cases, there was no mention of any work in press.

Until recently, it was unconscionable for any research group to present their advances via press release, and it is still (presumably) taboo for an academic group to announce their best work by way of a press release in the absence of a formal presentation of the work in the scientific literature.

This behavior is all the more surprising given the precedent set by the large pharmaceutical companies, who seem loath to announce their findings, be it by press release or full publication, until absolutely necessary. Witness, for example, the scientist who last year mentioned in an open meeting that his group had solved the crystal structure of a cytomegalovirus protease. Within months, at least four papers presenting the same structure appeared, within two weeks of each other, in Nature and Cell. Coincidence? Unlikely - the authors of those four papers were to be found at the pharmaceutical companies Boehringer Ingelheim, SmithKline Beecham, Monsanto/Searle and Agouron, and had presumably been sitting on the data for some time and only released it when they thought that someone would beat them to publication.
So what is behind the new behavior of biotechnology companies? Two of them mentioned that they feared charges of insider trading if employees exercised stock options while sitting on data that could affect their share value. An examination of what they have in common provides further insight into motive: All three mean to make their fortune by discovering genes; they are relatively young companies (four to six years old); they have gone public within the last two years; and they are all reliant on financing from major pharmaceutical firms. They also find themselves in a highly competitive and aggressive market, with a very limited product line and little or no security. Under these circumstances, financial issues are paramount and it seems likely that they were directing their announcements at backers and financial analysts rather than at the scientific community.

Should the scientific community be concerned with this trend? Probably not. The only potential damage is if the press releases contain useful data. This is unlikely, since although they want the publicity, they also have no desire to present their data before it is necessary, thus assuring them and their sponsors the greatest lead time to investigate therapeutic or other commercial options. The worst that might happen is that the newsworthiness of the eventual complete scientific publication of the work will be adversely affected by the earlier announcement. Certainly journals have no wish to see the news value of the material they publish diminished (particularly at a time when all the signs point to a growing awareness from academic researchers of the power of the media and importance of public recognition), but it seems unlikely that this would dictate a journal's decision to publish. Of course, if scientific facts crept into the press release, one could argue that the material had in part been previously reported and as such was not novel and was no longer an attractive publishing proposition.

Indeed, in publishing by press release, just as in science publishing, content is all, and as long as press releases stick to the hype and hyperbole, and skip hard facts, perhaps the best approach for the scientific community is simply to ignore the issue and let it work its magic on those with a purely financial interest in the technology. And make no mistake, press releases have an effect - following their May announcement, Sequana saw its stock rise more than $6 \%$.

Unfortunately, it is probably too much to ask that the academic research community leave all the fun to the commercial sector. As a research group approaches a period of competitive grant renewals or national research quality assessments, could it hurt to be on the front page of your local newspaper or mentioned on the wire services? Yet here perhaps is where most damage might be done. Research is already highly competitive, and coming in second place is increasingly seen as failure. Might we see academic research groups avoiding the race to publication by releasing their discoveries to the press and, by virtue of the slippery slope, adding more facts and figures to those releases so that peer review becomes merely an option? Could reporters report on science breakthroughs with any confidence, knowing that the press release came direct from the researcher and in the absence of the safety net that peer review and formal publication provides? And how would an already jaded public react to a fresh wave of exaggerated claims for imminent or promised breakthroughs? Publication by press release might have a place in helping fledgling biotechnology companies secure a financial future, but as a strategy for announcing important scientific breakthroughs, it is to be avoided. 